XUESONG FENG, Ph.D. ${ }^{1}$

(Corresponding author)

E-mail: xsfeng@bjtu.edu.cn

WEIXIN HUA, Master Student ${ }^{1}$

E-mail: 18120810@bjtu.edu.cn

XUEPENG QIAN, Ph.D. ${ }^{2}$

E-mail: qianxp@apu.ac.jp

${ }^{1}$ School of Traffic and Transportation

Beijing Jiaotong University

No.3 Shangyuancun, Haidian District, Beijing 100044,

P.R. China

2 College of Asia Pacific Studies

Ritsumeikan Asia Pacific University

1-1 Jumonjibaru, Beppu 874-8577, Japan
Science in Traffic and Transport

Preliminary Communication

Submitted: 11 Jan. 2019

Accepted: 30 May 2019

\title{
REDUCING PERCEIVED URBAN RAIL TRANSFER TIME WITH ORDINAL LOGISTIC REGRESSIONS
}

\begin{abstract}
In order to improve the transfers inside an Urban Rail Transit (URT) station between different rail transit lines, this research newly develops two Ordinal Logistic Regression (OLR) models to explore effective ways for saving the Perceived Transfer Time (PTT) of URT passengers, taking into account the difficulty of improving the transfer infrastructure. It is validated that the new OLR models are able to rationally explain probabilistically the correlations between PTT and its determinants. Moreover, the modelling analyses in this work have found that PTT will be effectively decreased if the severe transfer walking congestion is released to be acceptable. Furthermore, the congestion on the platform should be completely eliminated for the evident reduction of PTT. In addition, decreasing the actual transfer waiting time of the URT passengers to less than 5 minutes will obviously decrease PTT.
\end{abstract}

\section{KEY WORDS}

perceived transfer time; perceived transfer waiting time; ordinal logistic regression model; urban rail transit service improvement;

\section{INTRODUCTION}

Frequent car usage not only increases the detrimental effect on the environment [1-3] but also makes car users involved in higher risks of traffic accidents especially in the developing countries [4, 5]. Facing up to more and more serious traffic problems caused by frequent car usage, people are increasingly aware of the importance of changing their travel behaviour from excessively depending on cars to mainly using public travel modes [2, 6]. Though taking negative effect on the automotive industry which is, to some extent, important in national economy [7], such changes are encouraged by official policies [8, 9]. However, many people still prefer to utilise private cars in priority, mainly due to unsatisfactory transfers between public transit routes. It has been proven that the passengers will not be satisfied with public transport services they receive until their travel time reductions are commonly deemed worthy of the transfers they made [10-13]. In other words, convenient transfers at interchange stations are critical to successfully improving the public transport services $[12,14,15]$ by saving adequate travel time of the passengers $[13,16]$. Only in this way can it be possible for more people to abandon the use of private cars, in consideration of their negative attitudes towards making the transfers $[14,17]$. Therefore, substantially improving the transfer efficiency plays the key role in both enhancing public transport utilisation and encouraging travel mode redistribution $[11,18]$.

Nevertheless, various costs for the alterations or reconstructions of the transfer facilities which are ordinarily huge and immovable [19] are too big for Urban Rail Transit (URT) interchange stations which are, to a certain degree, the most important public transport infrastructures, especially in a big city and usually constructed underground. As a result, it will be very difficult for a URT station to objectively reduce the time costs of its users for their transfers between different URT lines inside the station after putting the station into operation. By contrast, reducing the negative influences upon the Perceived Transfer Time (PTT) of the passengers is a practicable and effective way to improve the transfer service inside a URT station. To this end, in view of the difference between the time consumed in reality and the perceived time cost [20], different effects of various factors on the perceived time costs for urban rail transfers have to be analysed in advance. 
Generally overestimated [21] and mainly affected by personal attributes of trip-makers (i.e. age, gender, income, and so on) as well as trip-related factors (i.e. total travel time, transfers, travel time period, waiting time, etc.) [22], the perceived time consumptions for travels have been studied for a long time. However, specific analyses on the perceptions of various time costs expensed in public transports are relatively fewer [23] but interesting. For instance, González et al. [23] found that the perceived travel time in tram is a function of both the commuter characteristics and the time consumed in other travel stages. Fan et al. [24] conducted a passenger survey and recorded the waiting passengers at different transit stops in videos to compare the perceived and actual waiting time, and discover that basic amenities at transit stops obviously reduce the perceived waiting time. Moreover, smartphone tracking was used by Delclòs-Alió et al. [22] to analyse the differences between the perceived and the objective time of the daily commutes to a suburban university campus, and the total time spent on the entire commute route has been found as the main variable affecting the differences.

In the relatively fewer but interesting works on the perceived time costs of the public transport passengers, studies on the perceived time consumed in transfers between different URT lines inside a URT station are particularly inadequate. The vague characteristic of the transfer time costs perceived by the URT passengers makes PTT of different passengers with various personal and travel attributes ordinarily evaluated with diverse time cost ranges, which increases the complexity of clarifying the correlations between PTT and its determinant factors. The values of not only PTT but also many of its influencing factors need to be discretized before the quantificational analysis of their correlations. Therefore, owing to its relative superiority in rationally interpreting the relationships between the discrete values of different variables, the Ordinal Logistic Regression (OLR) $[25,26]$ is utilised in this research to analyse the effect of different actions on reducing PTT of the URT passengers for the urban rail transfer service improvement.

The latter parts of this paper are organised as follows. The survey on the time costs for the urban rail transfers in Beijing is introduced in Section 2, and the survey data are analysed in this part. Thereafter, Section 3 develops two OLR models to interpret the cumulative probabilities of the PTT and the Perceived Transfer Waiting Time (PTWT), respectively. These two newly developed OLR models are applied in Section 4 to predict the probabilistic changes of PTT for different scenarios taking various actions for the improvement of the urban rail transfer service. Finally, Section 5 provides conclusions, suggests ways to reduce PTT of the URT passengers, and discusses some future research issues.

\section{DATA SURVEY}

The survey on PTT of the URT passengers was carried out from November $29^{\text {th }}, 2017$ to December $5^{\text {th }}, 2017$, at four locations (i.e. Xizhimen Capita Mall, Zhonguancun Plaza Shopping Mall, Xidan Joy City and Xihongmen LIVAT Shopping Centre) which are next to each of four metro stations in Beijing, respectively. Questionnaires were handed to people staying in the rest areas of these four locations after getting their permissions and ensuring that they had the urban rail transfer experiences within one week. There are three kinds of questions in the questionnaire. The first kind of questions investigate the age, educational background, occupation and income of the respondent. Moreover, the URT utilisation frequency is also questioned in the first kind of questions, because it is very likely to take effect on the accuracy of PTT, in consideration of its influence upon the travel time perception accuracy of the URT passengers [27]. The second kind of questions require people to describe the details of their latest URT travels, such as travel purpose, travel time period, familiarity with the transfer route and total time cost for their entire trips. The third kind of questions focus on the perceptions of people about the transfers in their latest URT travels, including perceived transfer time consumption, perceived walking distance and perceived waiting time. A total of 490 questionnaires were distributed and collected. There were 467 valid questionnaires obtained finally by removing 33 invalid ones.

It is indicated in Figure 1 that, with the increase of the actual transfer waiting time, the ratio of the samples with the overestimates decreases continually. Meanwhile, the samples underestimating the transfer waiting time keep increasing. Moreover, if the transfer waiting time in reality is approximately between 3 minutes ( $\mathrm{min}$ ) and $5 \mathrm{~min}$, the passengers are more likely to objectively perceive their transfer waiting time. Similar with the changing trends of the sample ratios of PTWT, the ratios of the samples which overestimate and underestimate the transfer walking time continue to decrease and increase, respectively, with the increase of the actual time spent in walking for transfer, as displayed in Figure 2. By contrast, Figure 3 shows that the ratio of the samples with the overestimates first increase sharply and, thereafter, decrease slowly with the increase of the transfer walking distance in reality. If the actual transfer walking distances are between 50 metres $(\mathrm{m})$ and $200 \mathrm{~m}$, the ratios of the samples overestimating the distances are always over $60 \%$. Totally different to the changing trend of the percentage of the samples overestimating the transfer walking distances, the ratio of the samples which underestimate the transfer walking distances keeps increasing slowly with the increase of the actual walking distance in transfer. 


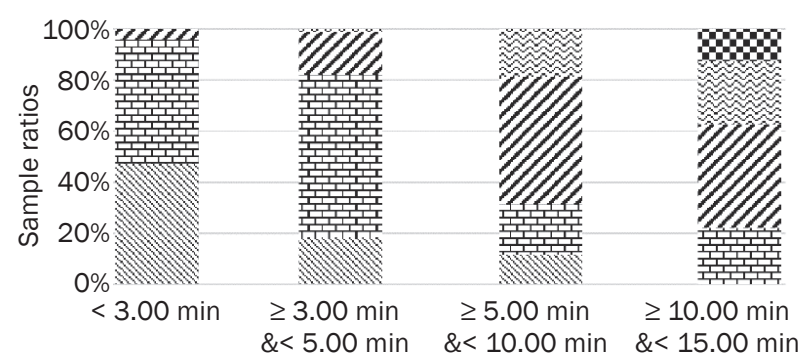

Actual transfer waiting time

$$
\begin{aligned}
& \text { 答 }<3.00 \mathrm{~min} \text { 岸 } \geq 3.00 \mathrm{~min} \&<5.00 \mathrm{~min} \\
& / \geq 5.00 \mathrm{~min} \&<10.00 \mathrm{~min} \approx \geq 10.0 \mathrm{~min} \&<15.00 \mathrm{~min} \\
& \text { Q: } \geq 20.00 \mathrm{~min}
\end{aligned}
$$

Figure 1 - Sample distribution based on perceived transfer waiting time

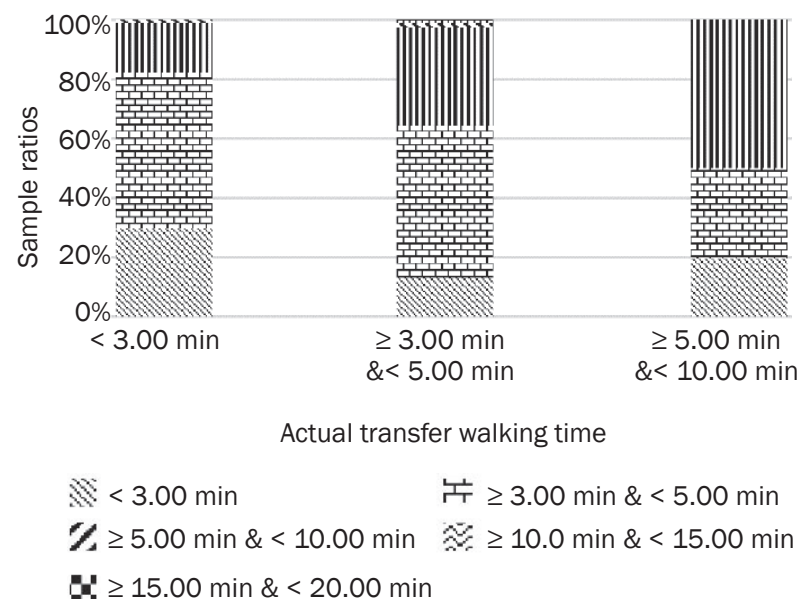

Figure 2 - Sample distribution according to perceived transfer walking time

\section{MODELLING STUDY}

\subsection{Model establishments}

Based on the sample survey in Beijing, two OLR models for PTT and PTWT have been developed, respectively. The effect of each factor investigated in the survey on PTT and PTWT is tested in the modelling work. The influencing variables of the finally established OLR models only include the effective factors. As explained by Equation 1, an OLR model is first established to interpret the relationship between the cumulative classification probability of PTT and the correlated variables. Moreover, as one of the most important factors of PTT, the PTWT classified in this research is also probabilistically explained by its related variables in Equation 2. These two OLR models work in cooperation to explain the changes of PTT and explore the effective ways of reducing PTT of the passengers for the urban rail transfer service improvement.

$$
\begin{aligned}
& \ln \left(\frac{\gamma_{i}^{T r T}}{1-\gamma_{i}^{T r T}}\right)=\alpha_{i}^{T r T}- \\
& \left(\begin{array}{l}
\beta^{G e^{r}} \cdot G e^{r}+\sum_{j=1}^{n^{E n T}-1} \beta_{j}^{T-E n^{p}} \cdot T_{j}^{E n^{p}}+\beta^{T-W k^{p}} \cdot T^{W k^{p}} \\
+\sum_{j=1}^{n^{W K D}-1} \beta_{j}^{D-W k^{r}} \cdot D_{j}^{W k^{r}}+\sum_{j=1}^{n^{W} T-1} \beta_{j}^{T-W t^{p}} \cdot T_{j}^{W t^{p}}+\sum_{j=1}^{n^{S t}-1} \beta_{j}^{S t^{r}} \cdot S t_{j}^{r} \\
\beta^{C o-W k^{p}} \cdot C o^{W k^{p}}+\sum_{j=1}^{n W t T-1} \beta_{j}^{W W} \cdot T_{j}^{W t^{p}} \cdot T^{W k^{p}}+\sum_{j=1}^{n^{S t}-1} \beta_{j}^{S C} \cdot S t_{j}^{r} \cdot C o^{W k^{p}}
\end{array}\right)+\varepsilon^{T r T}
\end{aligned}
$$

where:

$\gamma_{i}^{T r T}$ - cumulative probability of all the PTT costs belonging to the classes no bigger than Class $i$;

$\alpha_{i}^{T r T}$ - constant term for all the PTT costs belonging to the classes no bigger than Class $i$;

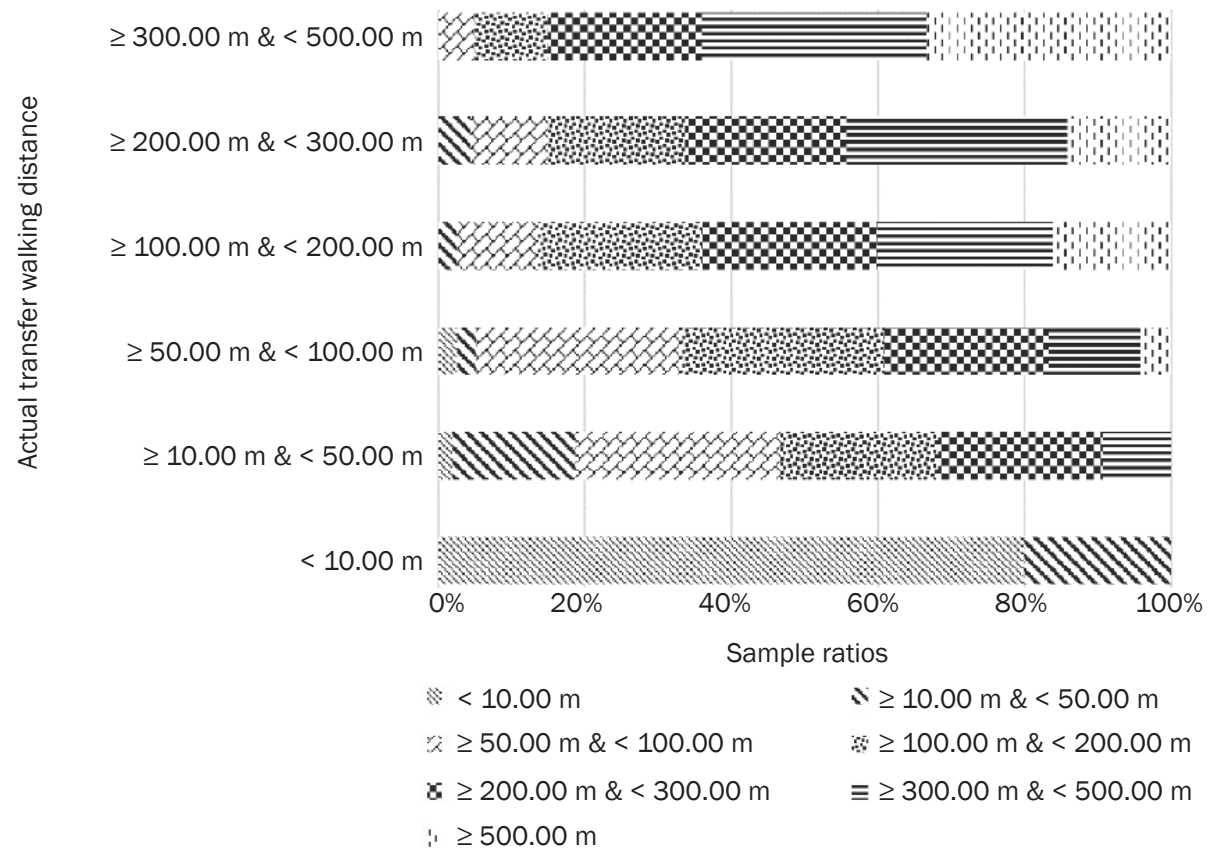

Figure 3 - Sample distribution on the basis of perceived transfer walking distances 
$G e^{r} \quad$ - 0-1 variable denoting that the gender of a passenger making a transfer is male (i.e. 1 ) or female (i.e. 0);

$T_{j}^{E n^{p}} \quad$ - 0-1 variable representing if the perceived time consumption for an entire trip is at Level $j$ (i.e. 1) or not (i.e. 0);

$n^{E n T}-$ number of all the levels for the perceived time costs of entire trips;

$T^{W k^{p}}$ - categorical variable explaining various perceived transfer walking times;

$D_{j}^{W k^{r}}$ - 0-1 variable which denotes if the actual transfer walking distance is at Level $j$ (i.e. 1) or not (i.e. 0);

$n^{W k D}$ - number of all the levels for the transfer walking distances in reality;

$T_{j}^{W{ }^{P}} \quad$ - 0-1 variable indicating whether the PTWT is at Level $j$ (i.e. 1) or not (i.e. 0);

$n^{W t T}$ - number of all the levels for the PTWT

$S t_{j}^{r} \quad$ - 0-1 variable denoting if the quantity of all the stairs utilised in a transfer is at Level $j$ (i.e. 1) or not (i.e. 0);

$n^{S t} \quad$ - number of all the levels for the quantities of the utilised stairs;

$C o^{W k^{p}}$ - categorical variable interpreting different perceived congestion degrees for walking in a transfer, and

$+\varepsilon^{\operatorname{TrT}}$ - error term for the cumulative probability of the PTT. It is assumed in this research that $+\varepsilon^{T r T}$ follows the distribution of $N\left(0, \sigma_{1}^{2}\right)$. $\ln \left(\frac{\gamma_{k}^{W t T}}{1-\gamma_{k}^{W t T}}\right)=\alpha_{k}^{W t T}-$
$\left(\begin{array}{l}\theta^{T-W k^{p}} \cdot T^{W k^{p}} \sum_{j=1}^{n^{W k D}-1} \theta_{j}^{D-W k^{r}} \cdot D_{j}^{W k^{r}}+\theta^{T-W t^{r}} \cdot T^{W t^{r}} \\ +\sum_{j=1}^{n_{t} C O} \theta_{j}^{C O-P t^{p}} \cdot C_{j}^{P p^{p}}+\theta^{W W} \cdot T^{W k^{p}} \cdot T^{W t^{r}}\end{array}\right)+\varepsilon^{W t T}$

where,

$\gamma_{k}^{W t T}$ - cumulative probability of all the PTWT costs belonging to the classes no bigger than Class $k$;

$\alpha_{k}^{W t T}$ - constant term for all the PTWT costs which belong to the classes no bigger than Class $k$;

$T^{W t^{r}}$ - categorical variable interpreting different actual transfer waiting times;

$\mathrm{Co}_{j}^{P^{t}}{ }^{p}$ - 0-1 variable indicating whether the perceived congestion degree on the platform for boarding a train is at Level $j$ (i.e. 1) or not (i.e. 0), and

$\varepsilon^{W t T}$ - error term for the cumulative probability of the PTWT. In this study, the distribution of $\varepsilon^{W t T}$ is hypothesized to follow $N\left(0, \sigma_{2}^{2}\right)$.

Various value ranges of both PTT and PTWT are interpreted in Table 1 for their different classes in this work. Moreover, Table 2 explains the corresponding conditions of different levels for the 0-1 variables in Equations 1 and 2. In addition, all the values of the categorical variables in the two newly developed models are interpreted in Table 3 for their different conditions

Table 1 - Conditions of different classifications for PTT and PTWT (Unit: min)

\begin{tabular}{|c|c|c|c|c|c|}
\hline Probability variable & Corresponding variable & Class 1 & Class 2 & Class 3 & Class 4 \\
\hline \hline$\gamma_{i}^{T r T}$ & PTT & $(0.00,5.00)$ & {$[5.00,10.00)$} & {$[10.00,15.00)$} & $(15.00,+\infty)$ \\
\hline$\gamma_{k}^{W t T}$ & PTWT & $(0.00,3.00)$ & {$[3.00,5.00)$} & $(5.00,+\infty)$ & - \\
\hline
\end{tabular}

Table 2 - Conditions of different levels for 0-1 variables

\begin{tabular}{||c|l|c|c|c|c||}
\hline \hline 0-1 variable & \multicolumn{1}{|c|}{ Level basis } & Level 1 & Level 2 & Level 3 & Level 4 \\
\hline \hline$T_{j}^{E n^{p}}$ & Perceived entire trip time [h] & $(0.00,1.00)$ & {$[1.00,2.00)$} & {$[2.00,+\infty)$} & - \\
\hline$D_{j}^{W k^{r}}$ & $\begin{array}{l}\text { Actual transfer walking distance } \\
{[\mathrm{m}]}\end{array}$ & $(0.00,100.00)$ & {$[100.00,200.00)$} & {$[200.00,300.00)$} & $(300.00,+\infty)$ \\
\hline$T_{j}^{W t^{p}}$ & PTWT [min] & $(0.00,3.00)$ & {$[3.00,5.00)$} & {$[5.00,+\infty)$} & - \\
\hline$S t_{j}^{r}$ & $\begin{array}{l}\text { Quantity of utilised stairs in a } \\
\text { transfer }\end{array}$ & 0 or 1 & 2 or 3 & 4 or more & - \\
\hline$C o_{j}^{P t^{p}}$ & $\begin{array}{l}\text { Perceived platform congestion } \\
\text { degree }\end{array}$ & D1 & D2 & D3 & - \\
\hline
\end{tabular}

Table 3 - Conditions of different values for the categorical variables

\begin{tabular}{||c|c|c|c|c|c||}
\hline \hline Categorical variable & Value basis & Value 1.00 & Value 2.00 & Value 3.00 & Value 4.00 \\
\hline \hline$T^{W k^{p}}$ & Perceived transfer walking time [min] & $(0.00,3.00)$ & {$[3.00,5.00)$} & {$[5.00,10.00)$} & $(10.00,+\infty)$ \\
\hline$C o^{W k^{p}}$ & Perceived walking congestion degree & D1 & D2 & D3 & - \\
\hline$T^{W t^{r}}$ & Actual transfer waiting time [min] & $(0.00,3.00)$ & {$[3.00,5.00)$} & {$[5.00,+\infty)$} & - \\
\hline
\end{tabular}


in correspondence. In Tables 2 and 3, D1 means that the congestion does not exist, D2 represents that there is acceptable congestion and D3 denotes that the congestion is serious.

\subsection{Model calibrations}

The newly established two OLR models are calibrated according to the maximum likelihood estimation [28]. As shown in Tables 4 and 5, the calibration results of both these two OLR models are acceptable from the perspective of statistics. Moreover, with the respective significances of 0.95 and 0.21 , they have also satisfyingly passed their Parallel Line tests [25]. Based on the calibration results for Equation 1, the Odds Ratio (OR) $[25,26]$ of $G e^{r}$ (i.e. $\exp \left(\beta^{G e^{r}}\right)$ which is approximately 0.58) indicates that the PTT costs of the male passengers are ordinarily less than those of the female ones for the same actual transfer time consumptions. The OR of $T_{1}^{E n^{p}}$ (i.e. $\exp \left(\beta_{1}^{T-E n^{p}}\right)$ which is about 0.31) means that, in comparison to the passengers with very long perceived time for their entire trips, the passengers who think that less time is spent

Table 4 - Calibration of Equation 1

\begin{tabular}{||c|c|c|c|c|c|c||}
\hline \multirow{2}{*}{ Parameter } & \multirow{2}{*}{ Estimated value } & \multirow{2}{*}{ Standard deviation } & \multirow{2}{*}{ Wald } & \multirow{2}{*}{ Sig. } & \multicolumn{2}{|c|}{$95 \%$ Confidence interval } \\
\cline { 5 - 7 } & & & & Lower limit & Upper limit \\
\hline \hline$\alpha_{1}^{T r T}$ & -0.40 & 1.20 & 0.11 & 0.74 & -2.75 & 1.96 \\
\hline$\alpha_{2}^{T r T}$ & 2.57 & 1.21 & 4.54 & 0.03 & 0.21 & 4.94 \\
\hline$\alpha_{3}^{T r T}$ & 5.14 & 1.24 & 17.18 & 0.00 & 2.71 & 7.57 \\
\hline$\beta^{G e^{r}}$ & -0.54 & 0.19 & 7.64 & 0.01 & -0.92 & -0.16 \\
\hline$\beta_{1}^{T-E n^{p}}$ & -1.16 & 0.50 & 5.27 & 0.02 & -2.14 & -0.17 \\
\hline$\beta_{2}^{T-E n^{p}}$ & -0.77 & 0.50 & 2.36 & 0.12 & -1.76 & 0.21 \\
\hline$\beta^{T-W k^{p}}$ & 0.77 & 0.33 & 5.31 & 0.02 & 0.11 & 1.42 \\
\hline$\beta_{1}^{D-W k^{r}}$ & -1.10 & 0.46 & 5.86 & 0.02 & -1.99 & -0.21 \\
\hline$\beta_{2}^{D-W k^{r}}$ & -0.95 & 0.44 & 4.75 & 0.03 & -1.80 & -0.10 \\
\hline$\beta_{3}^{D-W k^{r}}$ & -0.25 & 0.43 & 0.34 & 0.56 & -1.08 & 0.59 \\
\hline$\beta_{1}^{D-W t^{p}}$ & 2.59 & 1.04 & 6.24 & 0.01 & 0.56 & 4.62 \\
\hline$\beta_{2}^{D-W t^{p}}$ & 2.93 & 0.79 & 13.75 & 0.00 & 1.38 & 4.48 \\
\hline$\beta_{1}^{S r^{r}}$ & 0.82 & 0.30 & 7.47 & 0.01 & 0.23 & 1.41 \\
\hline$\beta_{2}^{S I^{r}}$ & -3.48 & 0.91 & 14.73 & 0.00 & -5.26 & -1.71 \\
\hline$\beta^{C o-W k^{p}}$ & -2.98 & 0.84 & 12.45 & 0.00 & -4.63 & -1.32 \\
\hline$\beta_{1}^{W W}$ & 1.23 & 0.40 & 9.30 & 0.00 & 0.44 & 2.02 \\
\hline$\beta_{2}^{W W}$ & 1.00 & 0.36 & 7.73 & 0.01 & 0.30 & 1.71 \\
\hline$\beta_{1}^{S C}$ & -0.83 & 0.44 & 3.63 & 0.06 & -1.69 & 0.02 \\
\hline$\beta_{2}^{S C}$ & -1.00 & 0.33 & 9.20 & 0.00 & -1.65 & -0.35 \\
\hline \hline
\end{tabular}

Table 5 - Calibration of Equation 2

\begin{tabular}{||c|c|c|c|c|c|c||}
\hline \multirow{2}{*}{ Parameter } & \multirow{2}{*}{ Estimated value } & \multirow{2}{*}{ Standard deviation } & \multirow{2}{*}{ Wald } & \multirow{2}{*}{ Sig. } & \multicolumn{2}{|c|}{ 95\% Confidence interval } \\
\cline { 5 - 7 } & & & & Lower limit & Upper limit \\
\hline \hline$\alpha_{1}^{W t T}$ & 2.68 & 0.77 & 12.21 & 0.00 & 1.18 & 4.18 \\
\hline$\alpha_{2}^{W t T}$ & 5.93 & 0.81 & 53.28 & 0.00 & 4.33 & 7.52 \\
\hline$\theta^{T-W k^{p}}$ & 1.06 & 0.31 & 11.63 & 0.00 & 0.45 & 1.67 \\
\hline$\theta_{1}^{D-W k^{r}}$ & -0.81 & 0.38 & 4.49 & 0.03 & -1.56 & -0.06 \\
\hline$\theta_{2}^{D-W k^{r}}$ & -0.98 & 0.37 & 6.97 & 0.01 & -1.70 & -0.25 \\
\hline$\theta_{3}^{D-W k^{r}}$ & -0.65 & 0.38 & 2.88 & 0.09 & -1.41 & 0.10 \\
\hline$\theta^{T-W t^{r}}$ & 2.70 & 0.44 & 37.18 & 0.00 & 1.84 & 3.57 \\
\hline$\theta_{1}^{C o-P t^{p}}$ & -1.13 & 0.38 & 8.78 & 0.00 & -1.87 & -0.38 \\
\hline$\theta_{2}^{C o-P t^{p}}$ & -0.21 & 0.21 & 1.06 & 0.30 & -0.62 & 0.19 \\
\hline$\theta^{W W}$ & -0.56 & 0.20 & 7.89 & 0.00 & -0.96 & -0.17 \\
\hline
\end{tabular}


on their entire trips, usually have relatively short PTT. In addition, the ORs of $D_{1}^{W k^{r}}$ (i.e. $\exp \left(\beta_{1}^{D-W k^{r}}\right)$ which is around 0.33) and $D_{2}^{W k^{r}}$ (i.e. $\exp \left(\beta_{2}^{D-W k^{r}}\right)$ which is approximately 0.39 ) prove that the URT passengers with relatively short actual walking distances in transfers commonly have less PTT.

Furthermore, on the basis of the calibration results shown in Table 4, the OR of $T^{W k^{p}}$ (i.e. $\left.\exp \left(\beta_{1}^{W W}\right)\right)$ is about 3.42 when the PTWT is less than $3 \mathrm{~min}$, and its $\mathrm{OR}\left(\right.$ i.e. $\left.\exp \left(\beta_{2}^{W W}\right)\right)$ is around 2.72 when the PTWT is over $3 \mathrm{~min}$ and no more than $5 \mathrm{~min}$. This indicates that more perceived transfer walking time normally makes more PTT especially if less PTWT is consumed, because PTT is comprehensively decided by the successive stages of a transfer. It is also found that, when 2 or 3 stairs are utilised in a transfer, the OR of $C o^{W k^{p}}\left(\right.$ i.e. $\left.\exp \left(\beta_{2}^{S C}\right)\right)$ is equal to approximately 0.37 . This suggests that, as a result of the effect of comprehensive transfer walking environment, the increase of the perceived walking congestion degree always has PTT increased easily if relatively many stairs are utilised in a transfer.

According to the calibration of Equation 2, the ORs of $D_{1}^{W k^{r}}$ (i.e. $\exp \left(\theta_{1}^{D-W k^{r}}\right)$ which is approximately 0.44$)$ and $D_{2}^{W k^{r}}$ (i.e. $\exp \left(\theta_{2}^{D-W k^{r}}\right)$ which is about 0.38) clarify that PTWT generally decreases slightly at first and, thereafter, increases with increasing the actual transfer walking distance. If the actual transfer walking distance is between $100 \mathrm{~m}$ and $200 \mathrm{~m}$, the passengers are more likely to have the least PTWT. Moreover, the OR of $C_{1}^{P t^{p}}$ (i.e. $\exp \left(\theta_{1}^{C o-P t^{p}}\right)$ which is around 0.32) indicates that a platform which is not congested makes passengers comfortable, which usually results in relatively short PTWT. In addition, it is also ensured by the calibrated value of $\theta^{W W}$, shown in Table 5, that PTWT is simultaneously determined by the successive stages of a transfer.

\subsection{Accuracy evaluations}

If the predicted classification probability of a PTT cost for a certain class is the biggest in comparison to its predicted probabilities for other classes, the PTT cost is predicted to belong to this class. The surveyed and predicted classes of an accurately predicted sample are the same to each other. In accordance with this principle, the model accuracy is evaluated by Equation 3. The surveyed classes of the PTT and PTWT samples in this study and their classes predicted by the newly developed two OLR models are compared in Tables 6 and 7, respectively. According to Equation 3, the accuracy of the PTT OLR model explained by Equation 1 is evaluated to be about $62.10 \%$ for all the 467 valid samples. Moreover, it is also found that this model is good at predicting the classes of the samples with the surveyed PTT which is at least $5 \mathrm{~min}$ and, at the same time, less than $10 \mathrm{~min}$. Its accuracy is around $79.63 \%$ for such samples. By comparison, in spite of its a little lower accuracy (i.e. approximately 59.53\%) for all the 467 valid samples, the PTWT OLR model interpreted by Equation 2 is still able to truly predict the classes of PTWT in general. Furthermore, in comparison to the accuracies for other PTWT classes, the best accuracy (i.e. about $67.22 \%$ ) of the PTWT OLR model is for the samples with PTWT which is at least 3 min but less than $5 \mathrm{~min}$.

$$
R_{a}=\frac{N_{a}}{N_{s}} \cdot 100 \%
$$

where,

$R_{a}$ - model accuracy;

$N_{a}$ - amount of accurately predicted samples, and

$N_{s}$ - amount of the samples for accuracy evaluation.

Table 6 - Distribution matrix of predicted and surveyed PTT classes

\begin{tabular}{|c|c|c|c|c|c|c|}
\hline \multirow{2}{*}{\multicolumn{2}{|c|}{ PTT }} & \multicolumn{4}{|c|}{ Predicted classes } & \multirow{3}{*}{$\begin{array}{c}\text { Summary } \\
115\end{array}$} \\
\hline & & \multirow{2}{*}{$\begin{array}{c}\text { Class } 1 \\
63\end{array}$} & \multirow{2}{*}{$\begin{array}{c}\text { Class } 2 \\
52\end{array}$} & \multirow{2}{*}{$\begin{array}{c}\text { Class } 3 \\
0\end{array}$} & \multirow{2}{*}{$\begin{array}{c}\text { Class } 4 \\
0\end{array}$} & \\
\hline \multirow{4}{*}{ Surveyed classes } & Class 1 & & & & & \\
\hline & Class 2 & 23 & 172 & 19 & 2 & 216 \\
\hline & Class 3 & 3 & 51 & 50 & 4 & 108 \\
\hline & Class 4 & 0 & 10 & 13 & 5 & 28 \\
\hline \multicolumn{2}{|l|}{ Summary } & 89 & 285 & 82 & 11 & 467 \\
\hline
\end{tabular}

Table 7 - Distribution matrix of predicted and surveyed PTWT classes

\begin{tabular}{|c|c|c|c|c|c|}
\hline \multirow{2}{*}{\multicolumn{2}{|c|}{ PTWT }} & \multicolumn{3}{|c|}{ Predicted classes } & \multirow{3}{*}{$\begin{array}{c}\text { Summary } \\
173\end{array}$} \\
\hline & & \multirow{2}{*}{$\begin{array}{c}\text { Class } 1 \\
100\end{array}$} & \multirow{2}{*}{$\begin{array}{c}\text { Class } 2 \\
71\end{array}$} & \multirow{2}{*}{$\begin{array}{c}\text { Class } 3 \\
2\end{array}$} & \\
\hline \multirow{3}{*}{ Surveyed classes } & Class 1 & & & & \\
\hline & Class 2 & 76 & 162 & 3 & 241 \\
\hline & Class 3 & 3 & 34 & 16 & 53 \\
\hline \multicolumn{2}{|l|}{ Summary } & 179 & 267 & 21 & 467 \\
\hline
\end{tabular}




\section{SCENARIO ANALYSES}

Based on both calibrated OLR models developed in the last Section, three scenarios are studied in this Section to analyse their effect on reducing PTT for the improvements of urban rail transfer services in Beijing, in consideration of the practicalities of different actions. Various actions taken in each of the scenarios are explained as follows.

Scenario 1: Release walking congestion. That is, decrease the categorical value of the perceived walking congestion degree of the URT passengers believing that the transfer walking environment is very congested from 3.00 to 2.00 (i.e. Decrease-S1A) and 1.00 (i.e. Decrease-S1B), respectively.

Scenario 2: Release waiting congestion. That is, decrease the perceived waiting congestion degree of the passengers regarding that the platform for boarding a train is very congested from Level 3 to Level 2 (i.e. Decrease-S2A) and Level 1 (i.e. Decrease-S2B), respectively.

Scenario 3: Decrease the actual transfer waiting time. That is, decrease the categorical value of the actual transfer waiting time which is no less than $5 \mathrm{~min}$ from 3.00 to 2.00 (i.e., Decrease-S3A) and 1.00 (i.e., Decrease-S3B), respectively, for the passengers in correspondence.

The effect of different actions on changing the PTT class distribution of the corresponding passengers is shown in Tables 8-10 for different scenarios, respectively. It is shown in Table 8 that, if the passengers who perceive that the transfer walking environment is very congested, are successfully convinced that the congestion degree has decreased to an acceptable value, some of them will believe that the time spent for their transfers is reduced from at least 15 min to less than $15 \mathrm{~min}$ but at least $10 \mathrm{~min}$. Meanwhile, some of the passengers who deem the transfer walking environment very congested will perceive that their transfer time is decreased from at least 5 min but less than
$10 \mathrm{~min}$ to less than $5 \mathrm{~min}$. However, at the same time, some of the passengers will believe that their PTT increases from at least $5 \mathrm{~min}$ but less than $10 \mathrm{~min}$ to at least $10 \mathrm{~min}$ but less than $15 \mathrm{~min}$.

If the passengers with the belief of a very congested transfer walking environment perceive that the congestion is disappearing, some of them will confirm that their PTT has been reduced from at least $15 \mathrm{~min}$ to less than 15 min but at least $10 \mathrm{~min}$, as shown in Table 8. On the contrary, some of the passengers will be sure of the increase of their PTT from at least $5 \mathrm{~min}$ but less than 10 min to at least 10 min but less than 15 min. Meanwhile, the passengers with PTT less than 5 min neglect such congestion release. As a result, it is indicated that the release of serious transfer walking congestion to an acceptable degree will effectively reduce PTT of some passengers, in view of lots of difficulties and relatively poor effect of eliminating the transfer walking congestion.

It is found in Table 9 that, if the URT passengers who are confident that the platform for boarding a train is very congested, perceive that the congestion is becoming acceptable, their PTT has no change. Only if the congestion on the platform disappears, an apparent share of these passengers will believe that their PTT is reduced from at least 5 min but less than 10 min to less than $5 \mathrm{~min}$, though a very minor part of these passengers trust that their PTTs increase from at least $5 \mathrm{~min}$, but less than $10 \mathrm{~min}$ to at least $15 \mathrm{~min}$. Therefore, it is confirmed that completely eliminating the congestion on the platform is very important not only for the PTT reductions of the URT passengers but also for their safety.

As explained in Table 10, with the decrease of the transfer waiting time in reality from no less than 5 min to at least $3 \mathrm{~min}$, but less than $5 \mathrm{~min}$ and, successively, less than $3 \mathrm{~min}$, more and more passengers who believe they spend at least $5 \mathrm{~min}$ in waiting for boarding the trains in transfers perceive that their transfer time has been reduced. Especially when the actual

Table 8 - Class distribution of PTT for Scenario 1

\begin{tabular}{||c|c|c|c||}
\hline Classes & Current distribution [\%] & Distribution after Decrease-S1A [\%] & Distribution after Decrease-S1B [\%] \\
\hline \hline Class 1 & 18.96 & 19.91 & 18.96 \\
\hline Class 2 & 59.72 & 56.87 & 57.35 \\
\hline Class 3 & 17.06 & 21.80 & 20.85 \\
\hline Class 4 & 4.26 & 1.42 & 2.84 \\
\hline
\end{tabular}

Table 9 - Class distribution of PTT for Scenario 2

\begin{tabular}{||c|c|c|c||}
\hline \hline Classes & Current distribution [\%] & Distribution after Decrease-S2A [\%] & Distribution after Decrease-S2B [\%] \\
\hline \hline Class 1 & 18.77 & 18.77 & 21.46 \\
\hline Class 2 & 64.37 & 64.37 & 61.30 \\
\hline Class 3 & 14.18 & 14.18 & 14.18 \\
\hline Class 4 & 2.68 & 2.68 & 3.07 \\
\hline
\end{tabular}


Table 10 - Class distribution of PTT for Scenario 3

\begin{tabular}{||c|c|c|c||}
\hline \hline Classes & Current distribution [\%] & Distribution after Decrease-S3A [\%] & Distribution after Decrease-S3B [\%] \\
\hline \hline Class 1 & 4.00 & 40.00 & 44.00 \\
\hline Class 2 & 88.00 & 60.00 & 56.00 \\
\hline Class 3 & 8.00 & 0.00 & 0.00 \\
\hline Class 4 & 0.00 & 0.00 & 0.00 \\
\hline
\end{tabular}

transfer waiting time decreases from at least 5 min to less than 5 min but at least 3 min, a very remarkable share of such passengers think so, in comparison to the effect of decreasing the transfer waiting time in reality from less than 5 min but at least 3 min to less than $3 \mathrm{~min}$. This makes it clear that reducing the waiting time of the passengers for boarding trains on the platforms in transfers to less than $5 \mathrm{~min}$ is significant for the decrease of PTT.

According to different impacts of applying various strategies on reducing PTT of the URT passengers, it is apparent that reducing the waiting time of the passengers for boarding the trains on the platforms in transfers to less than $5 \mathrm{~min}$ is the most effective one. In the second place, completely eliminating congestion on a platform is very important from the perspectives of both PTT reduction and passenger safety. In addition, releasing the transfer walking congestion to an acceptable level also contributes to the decrease of PTT. Sometimes, even if very frequent train services are provided to make it possible for the URT passengers to have less transfer waiting time, the congestion on the platform makes the passengers have to wait longer before boarding their connection trains. The PTT of the URT passengers will be much increased in such a case. As result, the congestion on the platform is easy to result in a serious increase of PTT and does a big harm to the satisfaction of passengers with the transfer service they receive.

\section{CONCLUSION}

In order to improve the urban rail transfer service, a survey on the PTT of the URT passengers in Beijing has been carried out first. Two OLR models have been accordingly developed to explore the effective ways of reducing PTT of the passengers, in consideration of the difficulty of the URT station infrastructure improvements and the superiority of the OLR analysis in explaining the correlations between variables with discrete values. It has been confirmed that the newly developed models are able to rationally interpret the probabilistic changes of PTT with the values of its determining factors. It is found that PTT of the URT passengers will be effectively decreased as long as the serious congestion during walking in transfer is acceptable. In contrast, eliminating the congestion on the platform is essential to the valid decrease of PTT. Moreover, reducing the actual transfer waiting time of the passengers on the platform to less than 5 min will obviously decrease PTT. In addition, according to the survey on PTT, providing time information along the transfer routes may reduce PTT as well.

In view of the serious negative influence of the congestion on the platform upon PTT, it is suggested that, in the peak hours of urban rail operations, besides adequately decreasing the headways of the train services, the guidance on the platform needs to be evidently improved to reduce the congestion as much as possible. In contrast, in the non-peak hours, smoothly cooperative arriving and departing time of the trains operating on different rail transit lines is the key for the transfers of passengers to reducing their PTT efficiently. Due to limited human and financial resources, the number of the survey samples about PTT of the URT passengers in Beijing is not large. In future research, more URT passengers in Beijing will be surveyed to validate the results of this research. Moreover, the new OLR models developed in this research also need to be applied to analyse PTT of the URT passengers in different cities in the world to further improve their effectiveness.

\section{ACKNOWLEDGMENTS}

This study is supported by National Natural Science Foundation of China (71571011) and Fundamental Research Funds for the Central Universities (2018JBM022).

\section{冯雪松 ${ }^{1}$, 博士}

(通讯作者)

电子邮箱: xsfeng@bjtu.edu.cn

华炜欣 ${ }^{1}$, 硕士生

电子邮箱: 18120810@bjtu.edu.cn

钱学鹏 2 , 博士

电子邮箱: qianxp@apu.ac.jp

1 中国北京市海淀区上园村3号,

北京交通大学交通运输学院,

邮编: 100044

2 日本大分县别府市十文字原 $1-1$,

立命馆亚洲太平洋大学亚洲太平洋学部,

邮编: 874-8577

\section{摘要}

考虑到城市轨道交通车站换乘设施更新的困难性, 为 提高城市轨道交通换乘服务的质量, 本研究建立了两个新 的多项逻辑回归模型, 以探求减少城市轨道交通乘客换乘 感知时间的有效方法。新建立的多项逻辑回归模型能够从 
概率推理的角度, 合理地解释城市轨道交通乘客换乘感知 时间与其影响因素之间的关系。研究发现在换乘走行过程 中，若拥挤程度缓解至换乘乘客可接受，则乘客的换乘感 知时间将有效减少。此外, 为了切实地减少城市轨道交通 乘客换乘感知时间，城市轨道交通车站站台应避免人员拥 挤的情况发生。另外，如果能使乘客在其换成过程中的实 际等待时间少于五分钟, 则乘客的换乘感知时间将明显减 少。在未来的研究中, 新建立的多项逻辑回归模型仍需应 用于不同城市的轨道交通乘客换乘感知时间分析，从而更 近进一步地完善研究成果。

\section{关键词}

换乘感知时间; 换乘等待感知时间; 多项逻辑回归模型; 城市轨道交通服务提升

\section{REFERENCES}

[1] Sun Y, Yu X, Bie R, Song H. Discovering time-dependent shortest path on traffic graph for drivers towards green driving. Journal of Network and Computer Applications. 2017;83: 204-212. Available from: doi:10.1016/j.jnca.2015.10.018

[2] Şimşekoğlua Ö, Nordfjærnb T, Rundmobc T. The role of attitudes, transport priorities, and car use habit for travel mode use and intentions to use public transportation in an urban Norwegian public. Transport Policy. 2015;42: 113-120. Available from: doi:10.1016/j. tranpol.2015.05.019

[3] Wu W, Li PK, Zhang Y. Modelling and simulation of vehicle speed guidance in connected vehicle environment. International Journal of Simulation Modelling. 2015;14(1): 145-157. Available from: doi:10.2507/ IJSIMM14(1)CO3

[4] Ernstberger A, Joeris A, Daigl M, Kiss M, Angerpointnera K, Nerlich M, Schmucker U. Decrease of morbidity in road traffic accidents in a high income country - An analysis of 24,405 accidents in a 21 year period. Injury. 2015;46(Supplement 4): S135-S143. Available from: doi:10.1016/S0020-1383(15)30033-4

[5] World Health Organisation. Global Status Report on Road Safety: Supporting Decade of Action. Geneva: WHO Press; 2013. Available from: http://www.who.int/ iris/bitstream/10665/78256/1/9789241564564_ eng.pdf

[6] Birago D, Mensah So, Sharma S. Level of service delivery of public transport and mode choice in Accra, Ghana. Transportation Research Part F: Traffic Psychology and Behaviour. 2017;46(Part B): 284-300. Available from: doi:10.1016/j.trf.2016.09.033

[7] Liu S, Gong D. Modelling and simulation on recycling of electric vehicle batteries - u sing agent approach. International Journal of Simulation Modelling. 2014;13(1): 79-92. Available from: doi:10.2507/IJSIMM13(1)CO1

[8] Chowdhury S, Hadas Y, Gonzalez VA, Schot B. Public transport users' and policy makers' perceptions of integrated public transport systems. Transport Policy. 2018;61: 75-83. Available from: doi:10.1016/j.tranpol.2017.10.001

[9] Cools M, Fabbro Y, Bellemans T. Free public transport: A socio-cognitive analysis. Transportation Research Part A: Policy and Practice. 2016;86: 96-107. Available from: doi:10.1016/j.tra.2016.02.010

[10] Bryniarska Z, Zakowska L. Multi-criteria evaluation of public transport interchanges. Transportation Research Procedia. 2017;24: 25-32. Available from: doi:10.1016/j.trpro.2017.05.063

[11] Hernandez S, Monzon A, de Oña R. Urban transport interchanges: A methodology for evaluating perceived quality. Transportation Research Part A: Policy and Practice. 2016;84: 31-43. Available from: doi:10.1016/j.tra.2015.08.008

[12] Hernandez S, Monzon A. Key factors for defining an efficient urban transport interchange: Users' perceptions. Cities. 2016;50: 158-167. Available from: doi:0.1016/j.cities.2015.09.009

[13] Chowdhury S, Ceder A, Schwalger B. The effects of travel time and cost savings on commuters' decision to travel on public transport routes involving transfers. Journal of Transport Geography. 2015;43: 151-159. Available from: doi:10.1016/j.jtrangeo.2015.01.009

[14] Silva JA, Bazrafshan H. User satisfaction of intermodal transfer facilities in Lisbon, Portugal: Analysis with structural equations modelling. Transportation Research Record: Journal of the Transportation Research Board. 2013;2350: 102-110. Available from: doi:10.3141/2350-12

[15] Iseki H, Taylor BD. Style versus service? An analysis of user perceptions of transit stops and stations. Journal of Public Transportation. 2010;13: 23-48. Available from: doi:10.5038/2375-0901.13.3.2

[16] Bak M, Borkowski P, Pawlowska B. Types of solutions improving passenger transport interconnectivity. Transport Problems. 2012;7(1): 27-36. Available from: http://transportproblems.polsl.pl/pl/Archiwum/ 2012/zeszyt1/2012t7z1_03.pdf

[17] Guo Z, Wilson NHM. Assessment of the transfer penalty for transit trips: Geographic information system-based disaggregate modeling approach. Transportation Research Record: Journal of the Transportation Research Board. 2004;1872: 10-18. Available from: doi:10.3141/1872-02

[18] Aguiléra V, Allio S, Benezech V, Combes F, Milion $C$. Using cell phone data to measure quality of service and passenger flows of Paris transit system. Transportation Research Part C: Emerging Technologies. 2014;43(Part 2): 198-211. Available from: doi:10.1016/j.trc.2013.11.007

[19] Feng X, Wang X, Zhang H. Passenger transfer efficiency optimization modelling research with simulations. International Journal of Simulation Modelling. 2014;13(2): 210-218. Available from: doi:10.2507/ IJSIMM13(2)CO7

[20] Varotto SF, Glerum A, Stathopoulos A, Bierlaire M, Longo $\mathrm{G}$. Mitigating the impact of errors in travel time reporting on mode choice modelling. Journal of Transport Geography. 2017;62: 236-246. Available from: doi:10.1016/j.jtrangeo.2017.05.016

[21] Kelly P, Krenn P, Titze S, Stopher P, Foster C. Quantifying the difference between self-reported and global positioning systems-measured journey durations: A systematic review. Transport Reviews. 2013;33(4): 443-459. Available from: doi:10.1080/01441647.20 13.815288

[22] Delclòs-Alió X, Marquet O, Miralles-Guasch C. Keeping track of time: A Smartphone-based analysis of travel time perception in a suburban environment. Trave 
Behaviour and Society. 2017;9: 1-9. Available from: doi:10.1016/j.tbs.2017.07.001

[23] González RM, Martínez-Budría E, Díaz-Hernández JJ, Esquivel A. Explanatory factors of distorted perceptions of travel time in tram. Transportation Research Part F: Traffic Psychology and Behaviour. 2015;30: 107-114. Available from: doi:10.1016/j.trf.2015.02.006

[24] Fan Y, Guthrie A, Levinson D. Waiting time perceptions at transit stops and stations: Effects of basic amenities, gender, and security. Transportation Research Part A: Policy and Practice. 2016;88: 251-264. Available from: doi:10.1016/j.tra.2016.04.012
[25] Kremelberg D. Practical Statistics: A Quick and Easy Guide to SPSS, STATA, and Other Statistical Software. Thousand Oaks: Sage Publications, Inc.; 2010.

[26] Borooah VK. Logit and Probit: Ordered and Multinomial Models. Thousand Oaks: Sage Publications, Inc.; 2002.

[27] Van Exel N, Rietveld P. Perceptions of public transport travel time and their effect on choice-sets among car drivers. Journal of Transport and Land Use. 2010;2(3): 75-86. Available from: doi:10.5198/jtlu.v2i3.15

[28] Chambers RL, Steel DG, Wang S, Welsh AH. Maximum Likelihood Estimation for Sample Surveys. Boca Reton: CRC Press; 2012. 